\title{
Produção e geração do CD Estratégias de Leitura Relatório de experiência integrada PUCRS/FALE/CELIN e CM Champagnat
}

\author{
*Vera Wannmacher Pereira \\ **Joelene de Oliveira de Lima
}

PALAVRAS CHAVES: Leitura e escrita, Estratégia de leitura, Aprendizado, Computador

\begin{abstract}
This text present the plot of an experience completely realized by the Reference of Lenguage Development Center (CELIN) from the "LETRAS" College of PUCRS and from Champagnat Maristas School with the goal of building Educational Computer games made by virtual mateiral of teaching and research.First, the facts previously built in the process are presented. Soon, the language teories, placed on the physicolanguage, on the linguistic texts and on the information technology are presented too. After, the process realized and the games made by the interactive product between the authors and the collaborators in the game facturing are soon related.And at last, comments are made by the authors about the developd experience.
\end{abstract}

\section{RESUMO}

Este texto apresenta o relato de experiência realizada integradamente pelo Centro de Referência de Desenvolvimento da Linguagem (CELIN) da Faculdade de Letras da PUCRS e pelo Colégio Marista Champagnat, com o objetivo de construir Jogos Educacionais computadorizados, elaborados como material virtual de ensino e pesquisa. Primeiramente, são apresentados os fatos que constituíram-se nos antecedentes do trabalho. São apresentados a seguir os pressupostos teóricos lingüísticos, situados na Psicolingüística e na Lingüística do Texto, e os da Informática. Posteriormente, são descritos brevemente o processo realizado e os jogos que resultaram como produto do processo interativo entre as autoras e os colaboradores que atuaram como co-autores/especialistas na fase de modelagem do jogo. Por último, são tecidos comentários pelas autoras sobre a experiência desenvolvida.

\section{ANTECEDENTES}

O trabalho objeto deste relato origina-se de uma dupla vertente - da PUCRS e do Colégio Marista Champagnat.

Em março de 2001, foi implantado na Faculdade de Letras da PUCRS um centro de pesquisa, ensino e extensão denominado Centro de Referência para o Desenvolvimento da Linguagem - CELIN. Considerando sua característica de tríplice ação integrada, buscou apoios para o desenvolvimento de projetos que envolvessem o fazer científicos, a participação dos acadêmicos de Letras e o atendimento de escolas da comunidade. Com apoio então da FAPERGS e do CNPq, esse Centro desenvolveu o Projeto "Aprendizado da leitura e da escrita através do computador, por alunos do Ensino Fundamental", com o objetivo de construir um software pedagógico dirigido a esse público, utilizá-lo em situações de ensino monitoradas por acadêmicos da 
disciplina de Língua Portuguesa do Curso de Letras e investigar seus efeitos para o aprendizado da leitura e da escrita dos escolares.

Por sua vez, o Colégio Marista Champagnat tem como uma de suas buscas o estímulo do computador como importante ferramenta para organização do ensino nas diversas áreas do conhecimento. O Laboratório de Informática, aparelhado com 50 computadores Pentium III, conectados à Internet, orienta continuadamente os professores para inclusão dessa ferramenta em suas ações pedagógicas. Encaminha também os próprios alunos para se utilizarem recursos oferecidos pela Informática. Como um desses recursos, utiliza o Everest, por constituir-se em software com razoável simplicidade e com possibilidades satisfatórias para o âmbito escolar.

A convergência dessas buscas oportunizou uma produtiva aproximação entre o CELIN e o CM Champagnat, com o objetivo de, associando conhecimentos de Linguiística e Informática, produzir e gerar um $\mathrm{CD}$, com base no Everest, que oportunizasse o aprendizado da leitura e da escrita por alunos do EF, atendendo assim às buscas dos dois segmentos maristas.

\section{FUNDAMENTOS LINGÜÍSTICOS}

Entre os diversos conceitos, o de leitura como processo cognitivo é o aqui assumido. Nessa acepção, ler significa fazer e testar hipóteses sobre o conteúdo, isto é, fazer antecipações sobre esse conteúdo. No caso de o leitor confirmar suas predições, ele segue o caminho iniciado. No caso de não confirmá-las, ele modifica o seu caminho (Kato, 1987).

Segundo esse ponto de vista teórico, o processo cognitivo de leitura se altera, a partir de algumas variáveis: objetivo da leitura, conhecimento prévio do conteúdo e das condições de produção do texto, tipo de texto e estilo cognitivo do leitor. Tais variáveis determinam o processo de leitura - ascendente ou descendente (Goodman, 1987).

O processamento cognitivo da leitura ocorre através de dois grupos básicos de estratégias - cognitivas e metacognitivas (Leffa, 1996). As ECL caracterizam-se pelos traços intuitivo e inconsciente, enquanto as EMCL caracterizam-se pela consciência, pela intenção de monitoramento do próprio processo.

Constituem-se em exemplos de ECL pressuposições intuitivas do leitor, tais como a de que o texto é a priori coerente, a de que determinadas ordenações são impossíveis, a de que a escrita, em nossa cultura, ocorre da esquerda para a direita.

Constituem-se em exemplos de EMCL situações de monitoramento, tais como a realização de comparações intencionais de elementos lingüísticos, de julgamentos lingüísticos, de autocorreções.

O exame dessas EL expõe os elementos que internamente as constituem . Tais elementos correspondem fundamentalmente às regras de coerência textual, coesão lexical e coesão gramatical.

Nessa perspectiva, trabalhar com estratégias de leitura implica trabalhar com estratégias cognitivas e estratégias metacognitivas, que, por sua vez, implica trabalhar com regras de coerência textual, regras de coesão lexical, regras de coesão gramatical (Halliday,1976 e 1989; Koch, 1989; Charolles, 1978 e 1991) que se realizam diferentemente nos diversos tipos de texto - quanto à intencionalidade, ou predominantemente informativos ou predominantemente persuasivos ou predominantemente lúdicos, e, quanto à estrutura interna, ou predominantemente narrativos ou predominantemente descritivos ou predominantemente argumentativos. 
Os jogos construídos para o computador, dirigidos a alunos de $6^{\mathrm{a}}$. série do Ensino Fundamental, constituem-se em estratégias cognitivas e metacognitivas de leitura que se utilizam de regras de coerência e coesão, em textos de tipos diversos, tendo como suporte o ponto de vista de que a leitura é o caminho para a escrita, entendendo leitura não apenas como apreensão temática, mas como desvelamento do funcionamento lingüístico do texto (Orlandi, 1983). Essas convicções são sustentadas pelo entendimento de que o leitor é um escritor do texto do autor, isto é, de que aquele que lê também escreve, pois faz uma busca de reconstituição do caminho lingüístico do autor e, portanto, dos sentidos produzidos (Smith,1983,1991 e 1999). Desse modo, a leitura beneficia a própria leitura e, por decorrência, a escrita. Daí a sua dupla importância (Stotski, 1983).

É essa convicção que norteia o trabalho aqui relatado. Os jogos computacionais criados caracterizam-se como de leitura, ou melhor, como processo de leitura, traduzido esse processo, lingüisticamente, em manejo das regras de coerência e coesão textuais. A escrita (produção textual) ocorre como desdobramento do trabalho de leitura. A convicção aqui subjacente encontra defesa nas pesquisas que constatam que o domínio de regras de coerência e coesão na leitura favorece o domínio dessas mesmas regras na escrita (Poersch, 1993; Schneider,1993 ).

\section{FUNDAMENTOS DE INFORMÁTICA}

O ponto de vista de Informática Educativa do Colégio Marista Champagnat assumido é o de que, quando adotada na escola, deve se integrar ao currículo, não como uma disciplina, mas como uma ferramenta multidisciplinar, constituindo-se em alguma coisa a mais que o professor pode contar para bem realizar o seu trabalho, desenvolvendo atividades que levem a uma reflexão sobre qual a melhor forma de empregar seus recursos, analisando as características de cada disciplina, realizando a imprescindível interação entre as diversas disciplinas e os recursos da Informática.

Quando utilizada dessa maneira na escola, ou seja, a informática a serviço de um projeto educacional, propicia condições aos alunos de trabalharem a partir de temas, projetos ou atividades, surgidos no contexto da sala de aula. Em decorrência dessas situações os alunos podem contar com a interatividade e a programabilidade possibilitada pelo computador.

Assim sendo, a preocupação fundamental é a com o desenvolvimento de valores, com a concepção sobre as finalidades da educação e da convicção sobre a importância de formar um indivíduo com a inteligência desenvolvida, com cultura, flexível, crítico e criativo. A informática pode fazer parte desse universo, mas não pode ser encarada como um objetivo por si própria. O computador, como o livro ou qualquer outro material didático que usamos, é apenas e tão somente: um meio.

"Informação não é conhecimento. Você pode produzir dados primários em massa e incríveis quantidades de fatos e números. Mas não pode fazer produção em massa de conhecimento, que é criado por mentes individuais, separando o significativo do irrelevante, realizando julgamentos de valor. Theodore Roszak, autor do livro `O Culto da Informação"".

É, então, entendimento no trabalho aqui relatado que qualquer instrumento de ensino, desde o mais simples até o mais altamente elaborado, depende de quem o usa e de como isso é feito. Cabe ao professor a responsabilidade de diversificar a abordagem de seu componente curricular. A proposta para o uso do computador encontra-se no contexto das mudanças e 
evoluções

ocorridas

na

sociedade.

A escola não pode deixar de incorporar as novas transformações, intervindo para sistematizar a integração de todos os recursos pedagógicos e usando o que de melhor cada um tem para oferecer.

\section{PROCESSO DESENVOLVIDO}

Foi organizada, então, uma equipe constituída de professores das duas instituições e de bolsistas do CELIN, apoiados pela FAPERGS e pelo CNPq, conforme discriminação abaixo:

\section{CELIN/ FALE/PUCRS}

Coordenadora do Projeto:

Prof $^{\text {a }}$ Vera Wannmacher Pereira

Equipe de Produção do CD

CELIN: Produção técnica, pesquisa de campo e montagem:

Gislaine Nunes Barbosa (Bolsista FAPERGS 2001/2)

Ricardo Adornes Rodrigues (Bolsista CNPq 2001/2))

André Berg (Bolsista CNPq 2002/3)

Márcio Bastos Filho (participação especial: arte visual e musical)

\section{COLÉGIO MARISTA CHAMPAGNAT:}

Coordenação do Laboratório de Informática:

Prof. César de Lima Desimon

Montagem e Produção:

Prof $f^{a}$ Joelene de Oliveira de Lima

Aplicação em Língua Portuguesa:

Prof ${ }^{a}$ Simone C. Bernardo

A equipe assim constituída se reunia semanalmente no Laboratório de Informática do CM Champagnat.

Primeiramente foram discutidas as bases teóricas lingüísticas e examinados os jogos já anteriormente elaborados no Creative Writer, aplicados em crianças do Campus VNSF e apresentados em encontro de escolas maristas.

Posteriormente, foram tomadas decisões quanto ao software a ser utilizado. A escolha recaiu no Everest, ferramenta de autoria multimídia, que a escola havia recebido há pouco tempo e sobre cuja aplicação no contexto escolar a equipe já havia lido muito a respeito.

Passou a haver então um estudo aprofundado do seu uso e recursos, possibilitando o planejamento das etapas do trabalho e o início da modelagem dos jogos. O trabalho foi iniciado com o estabelecimento de um roteiro baseado em experiência e arquivos de texto anteriores apoiados no Creative Writer (processador de texto) e com a montagem de um banco de imagens e sons. 
A equipe passou então à execução do plano, tendo sido utilizado um longo tempo para isso, ultrapassando o previsto, considerando que a ferramenta não necessita de linhas de programação e a maior vantagem do uso do Everest é, justamente, a possibilidade de gerar executáveis de forma pouco complexa. No entanto, os detalhes de layout, a gravação do som, o próprio gerador do executável, os testes para ver se estava tudo funcionando ocuparam $70 \%$ do tempo dedicado ao trabalho. Depois veio a parte de validação/avaliação junto aos alunos. Eles mostraram-se muito receptivos e adoraram a atividade. Entenderam o funcionamento rapidamente e, ao final, queriam mais fases para "jogar".

Foi a primeira experiência desta equipe criando jogos desta forma, tendo a equipe desenvolvido um grande aprendizado. Após este trabalho outros jogos estão sendo criados para serem aplicados com outras séries.

Com a experiência e o desenvolvimento de várias aplicações definimos uma metodologia interna de trabalho, que é descrita a seguir:

a) Definição do Tema: Tópico a ser desenvolvido para que a tela tenha seu ponto de partida.

b)Roteiro e Plano de Ação: Subtemas e detalhes, plano onde conterá os dados tela a tela. Uma espécie de rascunho do trabalho final.

c)Pesquisa: Coleta de dados, análise e organização das informações, imagens, textos, vídeos, sons...

d)Registro das Informações Coletadas: Etapa técnica, digitação, organização dos dados para o computador

e)Apresentação: Demonstração do projeto para o grupo, criação de um CD com o executável do programa.

\section{DESCRIÇÃO DO “CD ESTRATÉGIAS DE LEITURA”}

O CD "Estratégias de Leitura" é constituído de 42 jogos de leitura, apresentando, em média, de 3 a 4 jogos por regra de coerência ou de coesão textual, sendo quatro regras de coerência, quatro regras de coesão lexical e cinco de coesão gramatical, conforme pode ser constatado na descrição que está apresentada a seguir:

R1 - Regra de Coerência: Manutenção Temática

"Você garante?" texto?

- Quando você escreve consegue garantir o mesmo assunto durante todo seu

Jogos: 'Joãozinho e o gato", 'Feijão delicioso"

R2 - Regra Coerência: Progressão Temática

"Passe adiante, senão é elefante. "

- Não basta ser o mesmo assunto, ele tem que ir adiante.

Jogos: 'O jornaleiro”, 'Os seis gangsters de Chicago”, 'O pirata” 
R3 - Regra de Coerência: Não-Contradição

\section{'Proibido proibir."}

- Isso não combina, combina? Pois é, isso não pode acontecer, né?

Jogos: “O Barba-Negra”, ”A centopéia ", 'Negócio da roça”

R4 - Regra de Coerência: Relação com o Mundo

\section{'Bruxa existe?'}

- Na nossa imaginação, sim.

Jogos: "Anúncios", 'Banho", "Certificado de garantia”, 'Preditibilidade”

R5 - Regra de Coesão Lexical - Repetição Lexical

"Repetindo, repetindo, repetindo."

- Repetir algumas palavras é necessário, mas não demais.

Jogos: 'Meu automóvel', 'O burro e o leão”, 'Rita, Rita”

R6 - Regra de Coesão Lexical : Sinonímia

"Velho é antigo?"

- Pelo menos nem sempre são a mesma coisa.

Jogos: "Os cisnes", “Futebol”, “O menino azul”, “ Os Morcegos”, “As vontades"

R7 - Regra de Coesão Lexical : Hiperonímia / Hiponímia

'Peixe-boi é peixe ou mamífero?'

- Por incrível que pareça, é um mamífero.

Jogos: 'Jardim da Igreja", 'Tão", "Coisas"

R8 - Regra de Coesão Lexical: Associação por Contigüidade

\section{'Sol combina com chuva?"}

- Somente no casamento da viúva.

Jogos: "Armandinho, o juiz", 'Bassê", 'Cantar, dançar, sonhar", "Ande legal, ande devagar"

R9 - Regra de Coesão Gramatical - Referência Pessoal

"Eu, tu ou ele?"

- Possivelmente nós. 
Jogos: 'Beija-flor”, 'Bicicleta”, 'O cavalinho branco", 'Ninho no coração”'

R10 - Regra de Coesão Gramatical - Referência Demonstrativa

'Este aqui ou aquele lá? Eu prefiro esse daí.’

- Depende de onde está.

Jogos: "Aviso de passeio da escola", "Aviso de entrega de boletins", "Azul e lindo Planeta Terra"

R11 - Regra de Coesão Gramatical - Elipse

‘ E eu... um sorvete!

- Eu o quê mesmo? Não entendi."

- Há uma palavra que não foi dita.

Jogos: 'O cúmulo", 'Vende-se, aluga-se, troca-se", 'Psicodélicas mangas"

R12 - Regra de Coesão Gramatical - Substituição

\section{"Sim ou não? Acho que talvez."}

- Sim não é pouco.

Jogos: "Anedota do João e da gata", "Barulhinhos do silêncio"

R13 - Regra de Coesão Gramatical - Conjunção

" Mas... e daí? E daí ... depois?"

- Mas não é pois.

Jogos: 'O Anjo”, ‘O lenço encantado”, 'Parece, mas não é”

Quanto à informatização dos jogos lingüísticos, cabe referir que o CD é composto por uma interface gráfica amigável constituída de várias imagens onde o aluno ao clicar realiza ações como acessar o exercício, responder as questões "arrastando" imagens ou palavras, navegando através de botões de ação.

Assim configurado, o CD é materialmente constituído de uma tela inicial geral, 13 telas de abertura dos blocos de conteúdo (regras de coerência e coesão) e 42 telas de jogos. Cabe dizer que, quanto ao seu uso, pode ocorrer na seqüência desejada pelo professor, uma vez que não se constituem em pré-requisitos entre si. 
Figura 1: Apresenta um a tela inicial da interface desenvolvida.
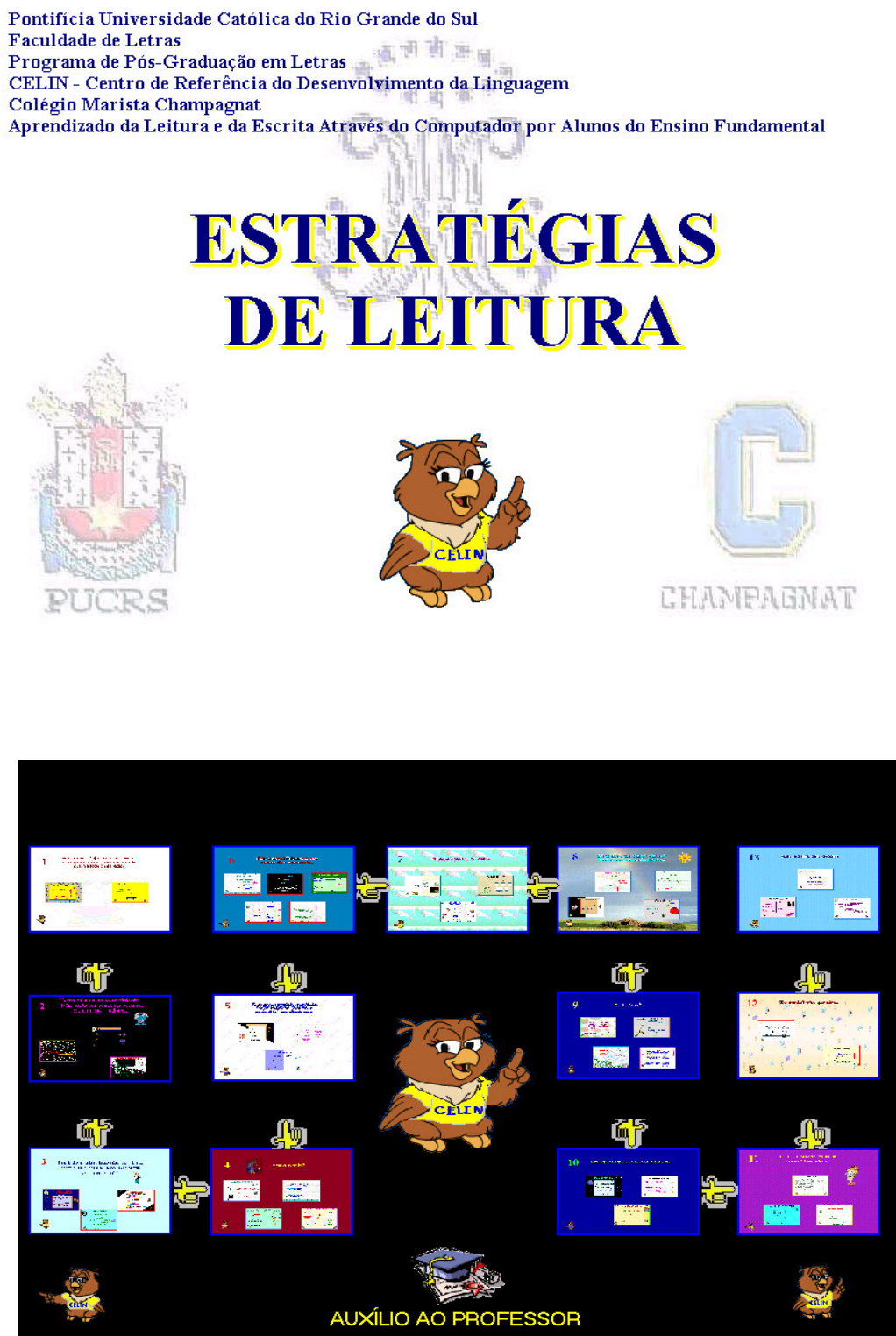

Figura 2: Interface de navegação e escolha da Regra ou exercício a ser realizado. 


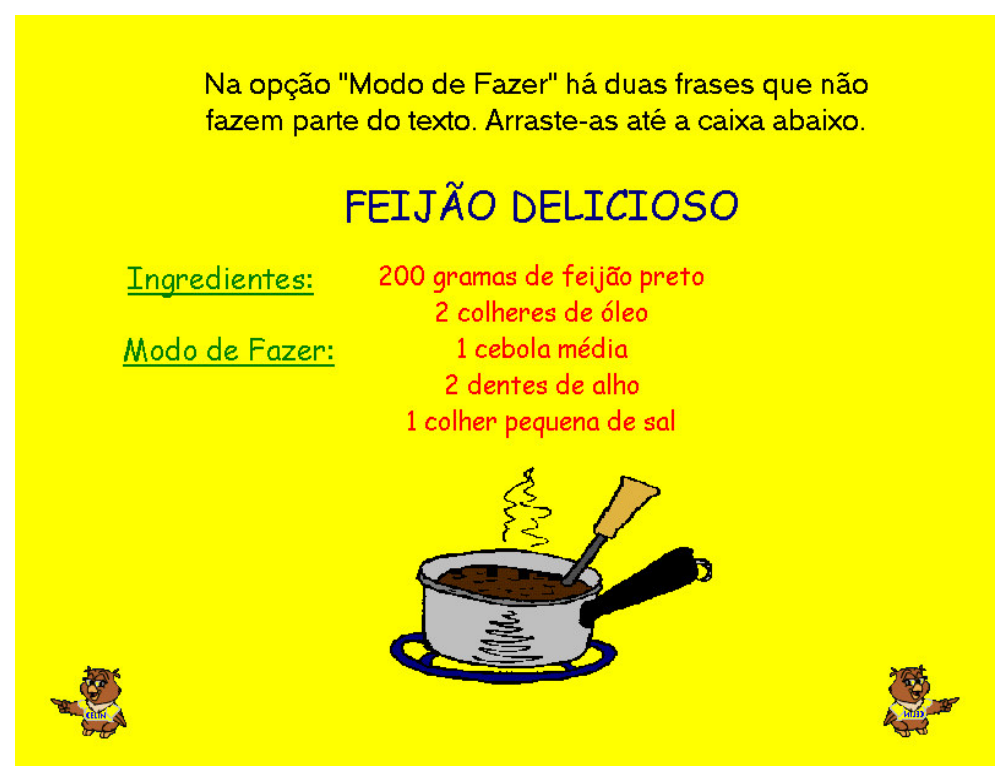

Figura 3: Interface de um jogo do CD apoiado na regra de coerência textual denominada manutenção temática

\section{COMENTÁRIOS}

A experiência desenvolvida foi especialmente significativa por um conjunto de motivos .

Um deles está relacionado ao fato de ter sido uma experiência integrada de produção de conhecimento, em múltiplas direções, associando instituições, ciência e tecnologia, áreas de conhecimento, teoria e prática, ensino e pesquisa, Universidade e Escola.

Outro está vinculado ao poder catalisador da experiência que atraiu professores e alunos das instituições, esses às vezes bolsistas, às vezes voluntários. Tal condição permitiu atrair para o trabalho os mais diversos talentos, todos igualmente indispensáveis para sua realização.

Pode ser apontado também como um deles a comprovação da possibilidade de produção harmônica de participantes com diferentes formações, níveis de titulação, experiências de aprendizagem e profissionais, uma vez que se evidenciou o conforto presente na equipe.

Cabe indicar como motivo relevante do ponto de vista científico-pedagógico a materialização de teorias inovadoras da Lingüística e da Informática em jogos lúdicopedagógicos ao mesmo tempo produtivos e agradáveis ao aluno.

Como motivo social, é importante registrar a contribuição social para escolas públicas e particulares, o que tem sido continuadamente comprovado através de ações que os acadêmicos vêm desenvolvendo nesses espaços pedagógicos, contribuindo para o desenvolvimento do aprendizado da leitura e da escrita.

Esse conjunto de motivos anima os participantes da experiência aqui relatada a dar-lhe continuidade e amplitude. 


\section{BIBLIOGRAFIA BÁSICA}

\section{Informática:}

ANDRADE, P.F. Et. al. Projeto Educom, Brasília: Ministério da Educação e Desportos e Organização dos Estados Americanos, 1993 a.

FREIRE, Fernanda Maria Pereira. Et al. A implantação da informática no espaço escolar. In: Revista Brasileira de Informática na Educação. Campinas: UNICAMP, 1998.

GAGLIARDO, A. F. O uso do computador em atividades de ensino. Tese de Mestrado. Faculdade de Educação. Campinas: UNICAMP, SP, 1985.

GARDNER,H. Inteligências Múltiplas. Porto Alegre: Artes Médicas, 1994.

MORAN, José M.A Escola do Amanhã: Desafio do Presente - Educação, Meios de Comunicação e Conhecimento. Tecnologia Educacional, v.22, n. 113/114, JUL/OUT 93. p. $28-38$

NOVOA, Antonio. Os professores e a sua formação. Liboa, Publicações Dom Quixote, Instituto de inovação Educacional, 1995.

PAPERT, S. A máquina das crianças: repensando a escola na Era da Informática. Porto Alegre: Artes Médicas, 1994.

SANDHOLTZ, Judith Haymore - Ensinando com tecnologia: Criando salas de aula centradas nos alunos. Editora Artes médicas - 1997

SANTOS,N. Multimídia na Educação: da teoria à prática. Porto Alegre: SBC, 1995.

VALENTE, J. A. Diferentes usos do computador na educação. In: Computadores e conhecimento: repensando a educação. Campinas: Gráfica Central da UNICAMP, 1993 a.

Por que o computador na educação. In: Computadores e conhecimento: repensando a educação. Campinas: Gráfica Central da UNICAMP, 1993.

\section{Lingüística:}

CHAROLLES, M. Introduction aux problèmes de la cohérence des textes. Langue Française. Paris: Larousse, n.38, p.7-41, mai 1978.

. Le résumé de texte scolaire: fonctions et principles de élaboration. Pratiques, Meta, n. 72, dé. 1991. 1992.

DIJK, Teun A. Van. Cognição, discurso e interação. São Paulo: Contexto,

FONSECA, F.I \& FONSECA, J. Pragmática Lingüística e ensino do Português. Coimbra: Almedina, 1977.

GALVES, Charlotte; ORLANDI, Eni; OTONI, Paulo.(orgs.) O texto: escrita e leitura. Campinas : Pontes, 1988. 
GOODMAN, Kenneth S. O processo de leitura : considerações a respeito das línguas e do desenvolvimento In: FERREIRO, E. et al. (Eds.) Os processos de leitura e escrita: novas perspectivas. Porto Alegre : Artes Médicas, 1987. p. 11-22. 1976.

HALLIDAY, M. ${ }^{\text {a }}$ K. \& HASAN, R. Cohesion in English. London: Longman, . Language, context and text: aspects of language in a social-semiotic perspective. Oxford: Oxford University Press, 1989.

KATO, Mary. O aprendizado da leitura._São Paulo: Martins Fontes, 1987.

KINTSCH, W. \& VAN DIJK, T. A. Toward model of text comprehension and production. Psychological review, 1978.

KLEIMAN, Angela. Texto e leitor : aspectos cognitivos da leitura. Campinas : Pontes, 1989 (a).

. Leitura: ensino e pesquisa. São Paulo: Pontes, 1989 (b).

Oficina de leitura : teoria e prática. Campinas : Pontes, 1996.

KOCH, I. V. A coesão textual. São Paulo: Contexto, 1989.

. A inter-ação pela linguagem. São Paulo: Contexto, 1992.

LEFFA, Vilson. Aspectos da leitura: uma perspectiva psicolingüística. Porto Alegre: Sagra, 1996.

LETRAS DE HOJE . Implicações da Psicolingüística nos processos de produção e recepção do código escrito. Porto Alegre, EDIPUCRS, dez. 1991. V.86.

PEREIRA, Vera Wannmacher. Informática e leitura abraçadas. In: Mundo Jovem. Porto Alegre: Mundo Jovem, out. 1998 n.292, p.7

ORLANDI, Eni. A linguagem e seu funcionamento. São Paulo: Brasiliense, 1983.

POERSCH, J. M. \& AMARAL, M. P. Como as categorias textuais se relacionam com a compreensão em leitura. In: Veritas , n. 35, 1989.

POERSCH, J. Marcelino (org.). Pontos de convergência entre leitura e escritura. Porto Alegre: EDIPUCRS, 1993.

SCHNEIDER, Mirna. A correlação entre a compreensão das categorias de coesão textual e a produção de textos escritos coerentes. In: Letras de Hoje, n.92, jun de 1993.

SMITH, F. Reading like a writer. Language Arts, Urbana, v. 60, p. 558-567, may 1983.

. Compreendendo a leitura: uma análise psicolingüística da leitura e do aprender a ler. Porto Alegre: Artes Médicas, 1991.

Leitura significativa. Porto alegre: Artes Médicas, 1999.

SOLÉ, Isabel. Estratégias de leitura. Porto Alegre: Artes Médicas, 1999.

STOTSKY, S. Research on reading/writing relationships: a synthesis and suggested directions. Language Arts, Urbana, v.60, n.5, p. 42-62, may 1983. 